\title{
Evaluating the Risk of Unmanned Aircraft Ground Impacts
}

\author{
Konstantinos Dalamagkidis, Kimon P. Valavanis, Les A. Piegl
}

\begin{abstract}
Currently many countries are developing regulation to allow Unmanned Aircraft Systems (UAS) operations in their National Airspace System (NAS). Successful integration requires UAS to achieve, at a minimum, an equivalent level of safety to that of manned aviation. Safety is primarily defined in terms of the risk to human life, although potential collateral damages to property can also be taken into account. This paper presents a novel, general, quite conservative and rather simple method that calculates the probability of fatalities and the fatality rates associated with a ground impact. Spatial analysis results are presented that indicate where unmanned aircraft may fly based on obtained reliability and safety levels and provide a coherent comparison of reliability requirements between unmanned aircraft of different families.
\end{abstract}

\section{INTRODUCTION}

Unmanned Aerial Vehicles or Unmanned Aircraft Systems (UAS), as is the preferred term used by the Federal Aviation Administration (FAA), have demonstrated repeatedly major potential for diverse applications in military, civilian and public domains. Unfortunately, with the exception of military applications, lack of the necessary regulatory framework has impeded adoption of UAS in the civil/public domains and that potential remains largely unexploited.

Regulation of manned aviation is carried out though a code of requirements, usually in the form of standards that various aircraft subsystems and all stages of design, manufacture and operation of the final system must adhere to [1]. Nevertheless a safety net also exists in the form of provisions that define minimum safety levels used to evaluate new technologies or designs, not explicitly covered by existing code [2]. These requirements may be found in paragraph 1309 of current CS or the corresponding AMC sections and can be used as an initial approach to drafting the safety requirements for UAS.

Minimum safety levels for manned aviation are typically obtained based on the assumption that due to point-topoint operations a significant portion of their flight time is spent over less densely populated areas [3]. This same assumption does not hold for UAS, since especially for surveillance/patrolling applications they are required to loiter over specific areas. It is obvious that applying the safety level requirement obtained for manned aviation to UAS operating over areas of very low population (borders, forests, etc.), would impose unnecessarily conservative restrictions; on the contrary, if the UAS is required to loiter over a metropolitan area, the same safety level would be inadequate.

Several studies related to the risk to human life from debris impact, primarily after accidents involving space launch

The authors are with the Unmanned Systems Laboratory, Computer Science and Engineering Department, University of South Florida, 4202 East Fowler Avenue, ENB 118, Tampa, FL 33620
TABLE I

NOMENCLATURE

$\begin{aligned} \text { AMC } & \text { Acceptable Means of Compliance } \\ \text { CS } & \text { Certification Specification } \\ \text { EASA } & \text { European Aviation Safety Agency (European Union) } \\ \text { ELOS } & \text { Equivalent Level of Safety } \\ \text { FAA } & \text { Federal Aviation Administration (US) } \\ \text { MTOW } & \text { Maximum Take-Off Weight } \\ \text { NAS } & \text { National Airspace System } \\ \text { NTSB } & \text { National Transportation Safety Board } \\ \text { R/C } & \text { Remotely Controlled } \\ \text { RCC } & \text { Range Commanders Council } \\ \text { TLS } & \text { Target Level of Safety } \\ \text { UAS } & \text { Unmanned Aircraft Systems } \\ \text { USAR } & \text { UAV Systems Airworthiness Requirements }\end{aligned}$

vehicles, have been published in the past. Nevertheless there is only a handful of available studies regarding the risk to human life and property from accidents involving UAS. One well known such study is by Weibel and Hansmann, who investigated the risk of UAS ground impact and mid-air collisions in the US [4], and proceeded with an evaluation of possible risk mitigation measures [5]. Several years before Weibel and Hannsmann, McGeer et al, investigated the risk imposed by the operation of the Aerosonde UAS after a midair collision and after a ground impact accident [6], [7]. An analysis similar to Weibel's was carried out by Clothier et al, who investigated the risk to people after certain UAS accident scenarios over Australia [8], [9]. Hayhurst et al, identified the hazards stemming from UAS operations and presented their effect on regulatory efforts [10].

With the exception of Weibel's work [4], [5], the rest of the aforementioned studies base their analysis on a lethal area defined as a function of the aircraft size, assuming fatal injuries for all people within that area. This over conservative estimate was improved by Weibel and Hannsmann, who introduced a 'penetration factor' to account for the lower risk posed by smaller UAS and the protection offered by obstacles in the crash area. Nevertheless they don't provide a method to consistently calculate this penetration factor for different aircraft and for different scenarios.

This research aims to provide an improved model for assessing the probability of fatality after ground impact accidents involving UAS, using readily available UAS physical and operational characteristics and two parameters affecting the crash site: the population density and a sheltering factor. The proposed model builds upon and extends state-of-the-art published work [4]-[10] and provides a general method of quantitative risk evaluation that is applicable to all types of UAS families, and suitable for a wide range of scenarios. 
The paper begins with a discussion on defining appropriate target levels of safety, followed by a presentation of the proposed model for calculating the expected number of fatalities due to ground impact. Section IV provides an analysis of safety performance and reliability requirements for several types of UAS. The paper concludes with a discussion on obtained results.

\section{TARGET LEVELS OF SAFETY}

The procedure for defining safety constraints is based on the maximum acceptable likelihood of the worst possible outcome [12], in this case a fatality occurring either on the ground or on another aircraft due to a mid-air collision. This likelihood can then be used to define the TLS for the accident. If the latter is known, the UAS can be designed in such a way that the rate of occurrence of the hazards does not cause the accident rate to increase above the set level.

A prerequisite to defining target levels of safety (TLS) is determining acceptable level of risk from UAS operations as indicated in the following excerpt from paragraph 1309 of the NATO Airworthiness requirements [11]:

"The UAS system must be designed to reduce the risk to people including UAS crew, maintainers and third parties to a level acceptable to the certifying authority. It must also be designed to reduce the risk of material loss or damage to a level acceptable to the certifying authority."

Although the statement above assigns the responsibility of defining acceptable levels of risk to certifying authorities, the corresponding AMC section proposes a risk reference system for UAS as presented in Table II.

It is noteworthy that safety levels proposed by [11] allow a higher likelihood of events with the same severity than that allowed for manned civil aircraft. For manned aviation, an event that includes injuries and/or fatalities, is categorized as hazardous and as such it should be extremely remote $(<$ $10^{-7}$ events per flight hour) [13]. On the other hand, multiple fatalities are considered to be of catastrophic severity with a likelihood requirement of $10^{-9}$ or less [13]. It should be noted that fatality requirements for manned airplanes do not distinct between people on-board the aircraft as well as people on the ground.

Requirements above pertain to the occurrence of events that result in fatalities and they are not a direct measure of the fatality rate. As such, this approach is not readily applicable to define an equivalent level of safety (ELOS) for UAS since the expected fatalities between an accident involving only manned civil aircrafts and one that involves also a UAS can be different. Thus, since UAS are unmanned, it is proposed that safety constraints and an ELOS need be exclusively based on the fatality rate and determined considering only fatalities on the ground.

An analysis of NTSB accident data from 1984 to 2004 [8], presented in Table III, shows that ground fatalities in manned aviation, are only a very small percentage of the total fatalities and occur at a rate of about 1 per 10 million hours of flight. It should be noted that the exact number may vary depending on the type of aviation (general, regional/commuter, large) and the period over which the data are averaged [8]. This is also evident from the analysis in [12] that presents a survey conducted by the US Navy for ground casualties. Based on 10 million flight hours an average of 18, 7 and 4.7 fatalities is reported for US Navy, Commercial and General Aviation, respectively. The survey included data from 1980 to 1998 for US Navy flights and from 1982 to 1998 for civil aviation.

TABLE III

FATALITY RATES FROM ANALYSIS OF NTSB ACCIDENT DATA BETWEEN 1984 AND 2004. SOURCE: [8]

\begin{tabular}{c|c}
\hline Accident type & Accident rate $\left(\mathrm{hr}^{-1}\right)$ \\
\hline Total & $5.60 \cdot 10^{-5}$ \\
\hline Resulting in fatality & $1.09 \cdot 10^{-5}$ \\
\hline Resulting in fatality on the ground & $1.48 \cdot 10^{-7}$ \\
\hline
\end{tabular}

Considering the above, a fatality rate of $f_{F}=10^{-7} \mathrm{hr}-1$ or less is proposed for UAS that is consistent with that of manned aircraft.

However, lower or higher likelihoods have also been proposed. In [4] a limit of $10^{-8}$ is proposed to account for the fact that the benefits of UAS operations are not evident to the general public and as a result the tolerance for fatalities will be lower. In [9] analysis is based on multiple acceptable likelihoods ranging from $10^{-6}$ to $10^{-9}$. The Range Safety Criteria for UAS proposed a fatality rate of $10^{-6}$ or less based on the US Navy survey discussed previously [12], but their requirements are for military operations that allow higher fatality rates. Finally the NATO USAR also adopted the $10^{-6}$ rate, since it refers to any fatality as a catastrophic event [11].

Although the more conservative alternatives may be attractive, they can seriously impede commercialization of UAS as well as integration of their operations in the NAS. Therefore, a conservative evaluation of the risk from emerging hazards is preferable, since it can be later accommodated as flight hours accumulate and confidence in risk estimates improves.

The maximum acceptable frequency of accidents resulting in ground impact ( $\left.f_{\text {impact,max }}\right)$ is determined from (1) based on the expected number of fatalities, after a TLS for the fatality rate $\left(f_{F, \max }\right)$ has been set:

$$
f_{\text {impact,max }}=E(\text { fatalities } \mid \text { impact })^{-1} \cdot f_{F, \max }
$$

\section{EXPECTED Number of FATAlities Given UAS GROUND IMPACT}

Accurate estimation of the expected number of fatalities after a UAS ground impact requires a significant amount of information, ranging from the characteristics of structures in the area of the crash to the exact trajectory of the aircraft up to the point of impact.

Nevertheless for airworthiness regulation purposes a general approach is required to provide average estimates on the safety performance of a particular UAS. Such a method may take a number of factors into account, such as: 
TABLE II

UAS OPERATIONS RISK REFERENCE SYSTEM (THE GRAYED AREAS SIGNIFY UNACCEPTABLE RISK). SOURCE: [11]

\begin{tabular}{|l|l|l|l|l|l|l|}
\hline & & Catastrophic $^{a}$ & Hazardous $^{b}$ & Major $^{c}$ & Minor $^{d}$ & No safety effect \\
\hline \hline Frequent & $>10^{-3} / h r$ & & & & & \\
\hline Probable & $<10^{-3} / h r$ & & & & & \\
\hline Remote & $<10^{-4} / h r$ & & & & & \\
\hline Extremely remote & $<10^{-5} / h r$ & & & & & \\
\hline Extremely Improbable & $<10^{-6} / h r$ & & & & & \\
\hline
\end{tabular}

${ }^{a}$ Uncontrolled flight and/or uncontrolled crash, which can potentially result in a fatality. Potential fatality to UAS crew or ground staff.

${ }^{b}$ Controlled-trajectory termination or forced landing potentially leading to the loss of the UAS where it can be reasonably expected that a fatality will not occur. Potential serious injury to UAS crew or ground staff.

${ }^{c}$ Emergency landing of the UAS on a predefined site where it can be reasonably expected that a serious injury will not occur. Potential injury to UAS crew or ground staff.

${ }^{d}$ Slight reduction in safety margins or functional capabilities and slight increase in UAS crew workload.

- Kinetic energy imparted at impact: Needed to calculate the probability of fatal injuries to people exposed to the crash.

- Sheltering: Buildings, trees, vehicles and other obstacles can shelter a person from the impact, thus, reducing the probability for a serious injury or fatality.

- Population density: It is needed to determine the number of people exposed.

- Aircraft frontal area: It is used to determine the area affected by a crash.

- Percentage of voluntary versus involuntary exposure: It has been argued that higher fatality rates may be acceptable for people exposed voluntarily (e.g. the UAS operators) [8].

The expected number of fatalities can be determined using (2), where $N_{\text {exp }}$ is the number of people present in the crash area and as a result exposed to the accident:

$$
E(\text { fatalities } \mid \text { impact })=N_{\text {exp }} \cdot P(\text { fatality } \mid \text { impact })
$$

Assuming a uniform population density, $N_{\text {exp }}$ can be calculated by (3) as the product of that area $\left(A_{\text {exp }}\right)$ by the population density $(\rho)$ :

$$
N_{\text {exp }}=A_{\text {exp }} \cdot \rho
$$

There are several ways to determine the $A_{\text {exp }}$ based on impact characteristics. For a vertical crash this area may be approximated by the frontal area of the aircraft augmented by a small buffer to account for the width of an average human [14], whereas for a gliding descent it can be approximated by (4), where the wingspan and the length of the aircraft have been increased by the radius of an average person [8]:

$$
A_{\text {exp }}=W_{\text {aircraft }}\left[L_{\text {aircraft }}+\frac{H_{\text {person }}}{\sin (\text { glide angle })}\right]
$$

When the number of people exposed to the crash is known, the fatality probability given the exposure needs to be calculated, before determining the expected number of fatalities.

\section{A. Proposed fatality probability model}

The kinetic energy on impact has been used extensively as a measure of the probability of fatality, although other parameters may also influence it. Unfortunately, there is no consensus in the literature on how this relationship is best defined, as demonstrated by Fig. 1. Results of a study presented in RCC323 [12] shot that an $1 \mathrm{lb}$ object with kinetic energy of $50 \mathrm{~J}$ has a probability of causing a fatality of $10 \%$, while for more than $200 \mathrm{~J}$ that probability rises to above $90 \%$. According to studies in RCC321 [15], the corresponding kinetic energy estimates for an impact of a $1000 \mathrm{lb}$ object to the torso are approximately $40 \mathrm{~kJ}$ and $115 \mathrm{~kJ}$, respectively, a difference of three orders of magnitude from the previous model.

The aforementioned discrepancies can be attributed to the fact that kinetic energy does not correlate well with accident data [15]. Experimental data have shown that objects of different mass can have different effect on people, even if the kinetic energy imparted at the time of the impact is the same. Nevertheless a logistic curve based on the kinetic energy impact is considered a good model for fatality rate estimation [15].

It is also stated that the existing models are based on direct impact of an object to a person without taking into account that during an impact, some of the impact energy may be absorbed by buildings, trees, vehicles or other obstacles. In [4] the probability of fatality is given as a penetration factor that depends on the characteristics of the UAS and takes into account sheltering. But observing the four example penetration factors given by Weibel and Hannsmann [4] as illustrated in Fig. 1 for comparison purposes, it can be argued that their estimate for smaller vehicles is over conservative, since a fatality probability of $5 \%$ is assigned to a vehicle that weighs less than $100 \mathrm{gr}$, while, at the same time, the model underestimates the lethality of larger vehicles. Furthermore, as already mentioned, no method is provided to consistently estimate the penetration factor for other UAS.

Based on the observations above, a variation of the logistic growth model is proposed to estimate $P$ (fatality|exposure) as a function of kinetic energy at impact $\left(E_{i m p}\right)$ that also takes 


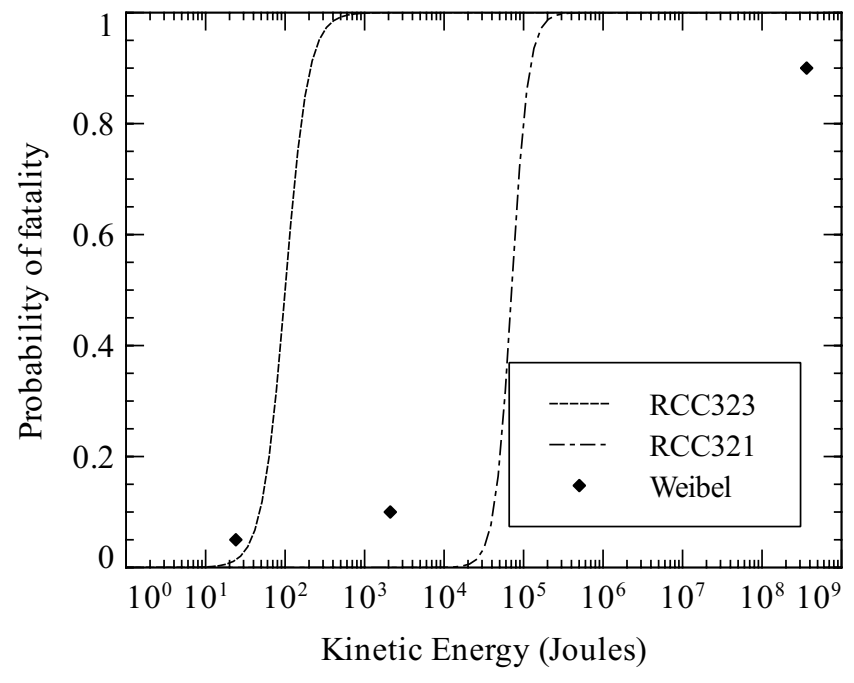

Fig. 1. The probability of fatality as a function of kinetic energy impact according to models derived from experimental data in RCC321 [15] and RCC323 [12]. Estimates used by Weibel and Hansmann [4] are also shown.

into account sheltering. The model is presented in (5) and depends on three parameters $\left(\alpha, \beta\right.$ and $\left.p_{s}\right)$ :

$$
P(\text { fatality } \mid \text { exposure })=\frac{1}{1+\sqrt{\frac{\alpha}{\beta}}\left[\frac{\beta}{E_{i m p}}\right]^{\frac{1}{4 p_{s}}}}
$$

The sheltering parameter $p_{s} \in(0,1]$ determines how exposed is the population to an impact. It takes an average value of 0.5 , with higher values meaning better sheltering and a lower probability of fatality for the same kinetic energy. The $\alpha$ parameter is the impact energy required for a fatality probability of $50 \%$ with $p_{s}=0.5$ and the $\beta$ parameter is the impact energy threshold required to cause a fatality as $p_{s}$ goes to zero. For small values of $p_{s}$ and appropriately chosen $\beta$, (5) can approximate accurately the curves in [12], [15]. Fig. 2 presents the curves generated from the proposed

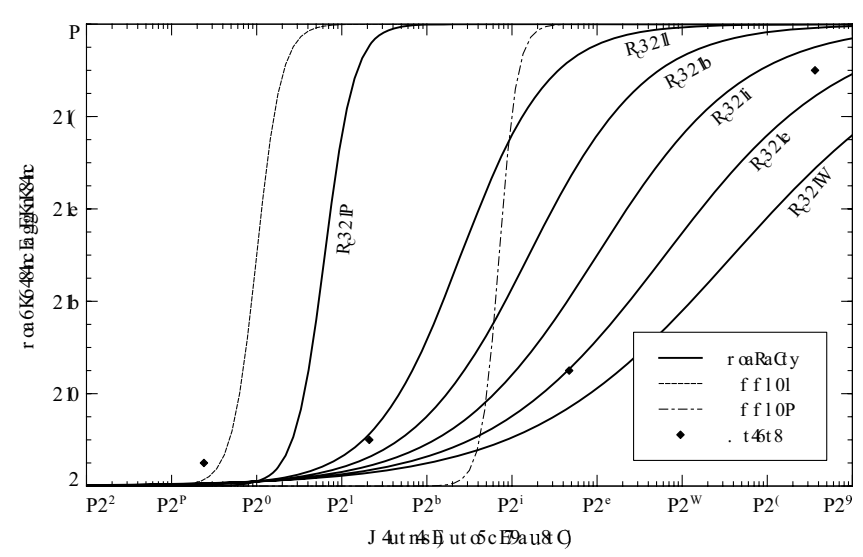

Fig. 2. The probability of fatality as a function of kinetic energy impact for the proposed model with $\alpha=10^{6} \mathrm{~J}, \beta=100 \mathrm{~J}$ and for several values of $p_{s}$. For comparison purposes the estimates of Weibel and Hannsmann [4] as well as the models of RCC321 [15] and RCC323 [12] are given. model for various values of the $p_{s}$ parameter.

The kinetic energy imparted at impact is a function of impact speed that may vary depending on the UAS and the trajectory of descent. A conservative approach is to use the terminal velocity that can be calculated from (6), where $m$ is the vehicle mass, $g$ is the acceleration of gravity, $\rho_{\alpha}$ is the air density, $A$ is the cross-sectional area of the vehicle and $C_{d}$ is its drag coefficient. The latter two parameters are not always available, since they may vary with the orientation of the aircraft during a descent:

$$
E_{i m p}=\frac{m^{2} g}{\rho_{\alpha} A C_{d}}
$$

In [1]-[3], instead of the terminal velocity, the use of the maximum operating velocity $\left(v_{o p}\right)$ increased by $40 \%$ is proposed, resulting in (7):

$$
E_{i m p}=m v_{o p}^{2}
$$

\section{UAS RISK EVALUATION}

The metric used to assess the risk involved from a ground impact, is the minimum acceptable period between ground impact accidents $\left(T_{G I}\right)$. This is calculated by combining (1), (2) and (5) obtaining (8), where the safety level was set to $10^{-7}$ and the parameters of the fatality probability model have been chosen to be $10^{6}$ and 100 for $\alpha$ and $\beta$, respectively:

$$
T_{G I, \min }=f_{G I, \max }^{-1}=\frac{A_{e x p} \rho}{1+100\left(\frac{100}{E_{\text {imp }}}\right)^{\frac{1}{4 p_{s}}}} \cdot 10^{7}
$$

As mentioned in the previous section, kinetic energy may be calculated either at terminal velocity or at the operational speed increased by $40 \%$. Although use of the terminal velocity is probably over-conservative, especially for small UAS flying at low altitudes, for the analysis that follows, both estimates are calculated and the most conservative is chosen.

The area exposed to the crash $\left(A_{\text {exp }}\right)$ for fixed-wing aircraft is estimated from (4) for a glide angle of $60^{\circ}$. For rotorcrafts the area will be calculated as $110 \%$ of the area of a circle with diameter equal to the rotor plus the average person width.

The $T_{G I}$ requirement was calculated for five UAS as well as a small $\mathrm{R} / \mathrm{C}$ helicopter. The characteristics of each of those vehicles are presented in Table IV and the obtained results are summarized in Table V.

\section{A. Case 1 - "Easy"}

The first case involves a UAS assisting in the surveillance of a storage facility or military installation. A low population density of 50 people per $\mathrm{km}^{2}$ is assumed along with a sheltering factor of .6 , since it can be assumed that people can be trained to avoid the UAS and/or protect themselves when required. 
TABLE IV

CHARACTERISTICS OF THREE FIXED WING AND TWO ROTORCRAFT UAS OF VARIOUS SIZES, AS WELL AS ONE R/C HELICOPTER, USED FOR THE CASE ANALYSIS. SOURCE: [16], [17]

\begin{tabular}{l|c|c|c|c|c}
\hline & Class & Weight $(\mathrm{kg})$ & Dimensions $(\mathrm{m})$ & Oper. Speed $(\mathrm{m} / \mathrm{s})$ & Oper. Altitude (ft) \\
\hline \hline RQ-4A Global Hawk & HALE & 11,612 & 35.4 (wingspan) & 177 & 65,000 \\
\hline MQ1 Predator & MRE & 1,021 & 14.8 (wingspan) & 70 & 20,000 \\
\hline Neptune & CRE & 36 & 2.1 (wingspan) & 43 & 8,000 \\
\hline RQ-6 Fire Scout & MRE & 1,157 & 8.4 (rotor diameter) & 65 & 20,000 \\
\hline Rmax IIG & CRE & 94 & 3.12 (rotor diameter) & 5.6 & 500 \\
\hline Maxi Joker 2 & Mini & 8 & 1.8 (rotor diameter) & $20^{a}$ & 400 \\
\hline
\end{tabular}

${ }^{a}$ guesstimated

TABLE V

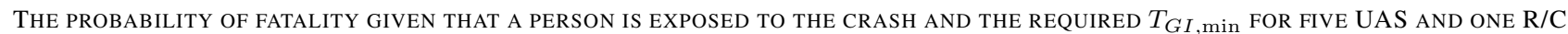
MODEL HELICOPTER UNDER VARIOUS SCENARIOS.

\begin{tabular}{l|c|c|c|c|c|c}
\hline & \multicolumn{2}{|c|}{ Case 1 } & \multicolumn{2}{c|}{ Case 2 } & \multicolumn{2}{c}{ Case 3 } \\
\cline { 2 - 7 } & $P($ fatality|exposure) & $T_{G I, \min }$ & $P$ (fatality|exposure) & $T_{G I, \text { min }}$ & $P($ fatality|exposure $)$ & $T_{G I, \text { min }}$ \\
\hline \hline RQ-4A Global Hawk & $84.4 \%$ & 236,377 & $99.2 \%$ & $27,781,594$ & $95.0 \%$ & $1,064,281$ \\
\hline MQ1 Predator & $55.7 \%$ & 43,916 & $93.4 \%$ & $7,358,637$ & $76.8 \%$ & 242,082 \\
\hline Neptune & $24.1 \%$ & 1,223 & $64.2 \%$ & 325,514 & $38.8 \%$ & 7,879 \\
\hline RQ-6 Fire Scout & $47.3 \%$ & 16,199 & $89.5 \%$ & $3,062,423$ & $68.9 \%$ & 94,241 \\
\hline Rmax IIG & $10.6 \%$ & 600 & $29.0 \%$ & 164,090 & $16.3 \%$ & 3,685 \\
\hline Maxi Joker 2 & $4.1 \%$ & 93 & $8.0 \%$ & 18,336 & $5.4 \%$ & 489 \\
\hline
\end{tabular}

\section{B. Case 2 - "Hard"}

The second case corresponds to the least favorable scenario of assisting in a search and rescue effort in a metropoli$\tan$ area. A high population density of 5,000 people per $\mathrm{km}^{2}$ is used combined with a sheltering factor of .4 , since several people will be in the open and preoccupied with other tasks. In this case the required $T_{G I \text {,min }}$ rises dramatically and becomes significant even for small UAS and prohibitive for larger vehicles.

\section{Case 3 - "Average"}

The last case corresponds to the average scenario used to evaluate manned aircraft of a standard population density of 200 people per $\mathrm{km}^{2}$ [3]. The sheltering factor chosen is 0.5 .

Although the risk analysis above is based on models that exhibit uncertainty and, therefore, are subject to error, the results do show an unquestionable advantage of light UAS in terms of safety with respect to full-scale UAS. On the other hand, derivation of more detailed models and especially validation of such models can be quite difficult because of the scarcity of accident data.

\section{Discussion}

Although the analysis that was carried out focused on the risk to human life, it should be noted that possible fatalities are not the only harm possible from UAS operations. As a result, in cases where the risk of fatalities from UAS operations is very low (e.g. low population areas, light UAS) considering only the worst possible outcome of a fatality may be inadequate. In these cases, a bottom-up approach may be warranted where all possible outcomes are considered and the required reliability levels are expected to be mostly cost-driven instead of safety-driven. This means that besides the target safety levels for the expected number of fatalities, target cost levels are also required to determine the minimum acceptable $T_{G I}$.

The cost of a UAS ground impact includes the cost of damages to the platform as well as damages to other property. Some UAS, depending on their size, may also carry dangerous payloads (chemicals, pyrotechnics for the fail-safe system) and/or significant quantities of fuel. After a crash, fire or chemical spillage is possible with measurable impact on the environment. Finally accidents near sensitive areas like schools or a high frequency of accidents in general, even when it is not accompanied by injuries or fatalities, can create discomfort to the general public and influence UAS operations in general. To control the cost and alleviate the other aforementioned issues, it can be expected that a maximum accident rate limit will be mandated regardless of the expected fatality rate from the operation of the UAS, especially for systems restricted to flying in remote, less populated areas.

Current manned aircraft have a $T_{G I}$ of $10^{5} \mathrm{hr}$ or better depending on the vehicle type [8], [16], [17], whereas contemporary operational UAS have been reported to have mishap rates of 1 to 2 orders of magnitude larger ${ }^{1}$ [18]. The majority of UAS accidents reported have been attributed to

\footnotetext{
${ }^{1}$ The accuracy of those rates is under question since it involves a limited number of platforms and the results have been extrapolated from a low number of flight hours.
} 


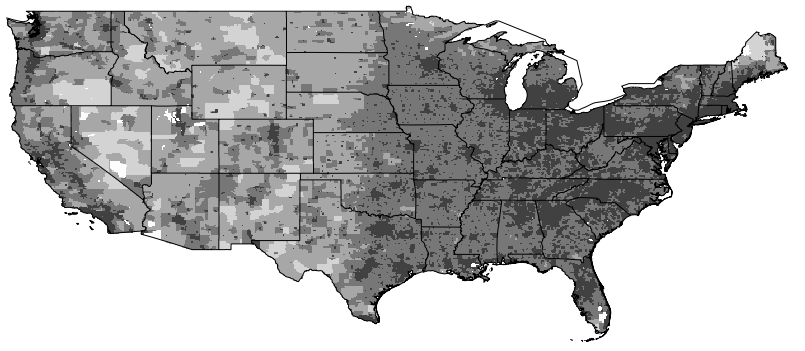

(a) RQ-4A Global Hawk

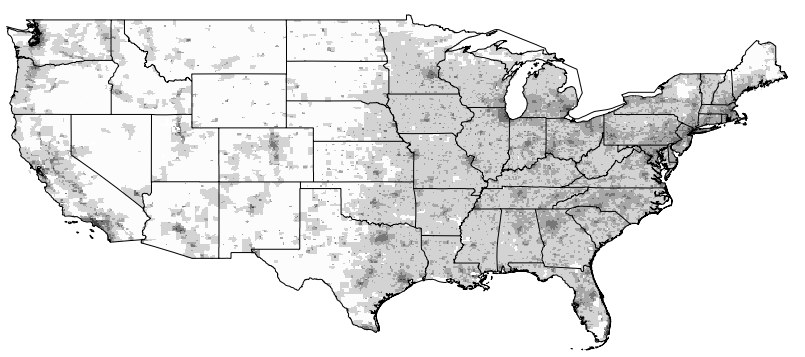

(c) Neptune

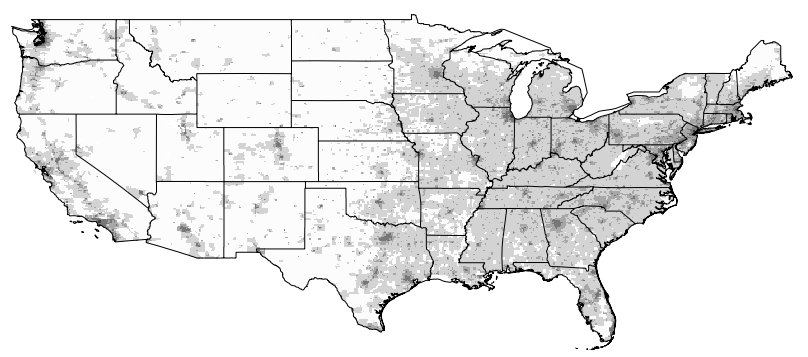

(e) Rmax IIG

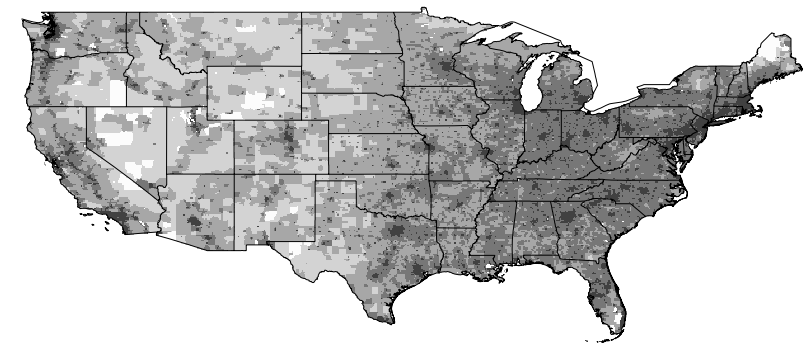

(b) MQ-1 Predator

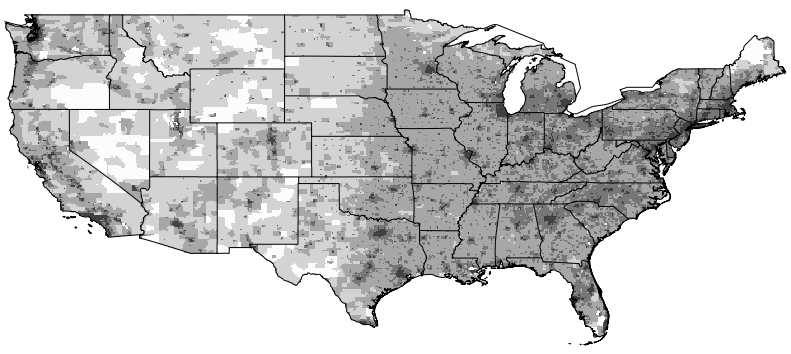

(d) RQ-6 Fire Scout

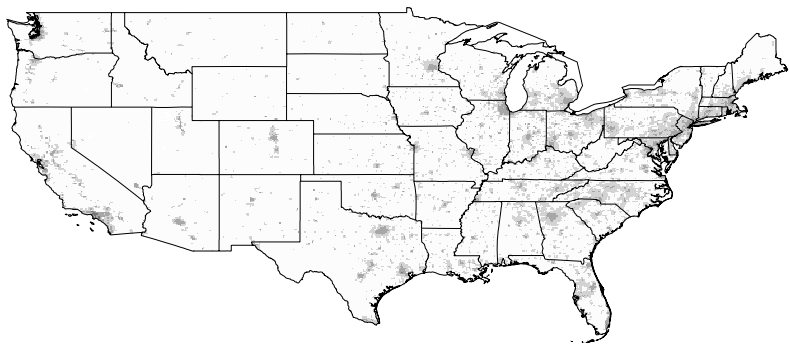

(f) Maxi Joker 2

\begin{tabular}{|ccccc|}
\hline \multicolumn{5}{|c|}{ Acceptable $T_{G I}$ in hours to overfly corresponding area } \\
\hline$<10^{2}$ & $10^{2}-10^{3}$ & $10^{3}-10^{4}$ & $10^{4}-10^{5}$ & $>10^{5}$ \\
\hline
\end{tabular}

Fig. 3. The areas of the US, UAS are allowed to overfly based on their reliability with respect to ground impact occurrence frequency.

power/propulsion failures [17]. Results of a study related to reasons causing UAS accidents are presented in Table VI.

TABLE VI

SOURCES OF FAILURES FOR US AND ISRAELI MiLITARY UAS: [17].

\begin{tabular}{l|c|c}
\hline & US & Israel \\
\hline \hline Power/Propulsion & $38 \%$ & $32 \%$ \\
Flight Control & $19 \%$ & $28 \%$ \\
Communications & $14 \%$ & $11 \%$ \\
Human/Ground & $17 \%$ & $22 \%$ \\
Misc & $12 \%$ & $7 \%$ \\
\hline
\end{tabular}

The increased accident rate means that there are a lot of areas where these systems are not or should not be allowed to fly due to safety reasons. For some of these systems, even if they reach the $100,000 T_{G I}$ limit, many areas, mostly over major cities, remain out-of-bounds.

Observing Fig. 3, for a large UAS like the RQ-6 Fire Scout, flight over most of the eastern continental US would pose a higher risk of fatalities than current manned avia- tion, even with a reliability rate of 10,000 hours between impacts. At the same time, a Maxi Joker $2 \mathrm{R} / \mathrm{C}$ helicopter is significantly less restricted. Similar results where obtained by doing the same analysis for Greece. Results, presented in Fig. 4, show that higher reliability requirements (darker areas) coincide with major population centers.

In general, smaller and lighter UAS offer a significant advantage since they pose a smaller risk to human life. Based on these results, an appropriate metric to classify UAS for safety regulation purposes is the Maximum TakeOff Weight (MTOW), since this is the main factor affecting the probability of fatality after an accident. NATO [11], EASA [3] and the UK CAA [19] have already defined light UAS as those with an MTOW of less than $150 \mathrm{~kg}$. Unfortunately this is not consistent with current manned aircraft classification for which two relevant categories have been defined by the FAA; Light Sport Aircraft (LSA) with an MTOW of up to $650 \mathrm{Kgr}$ and Ultralights with upper limit about $200 \mathrm{~kg}$ for powered and $150 \mathrm{~kg}$ for unpowered aircraft. At the same time the F.38 committee of the ASTM 


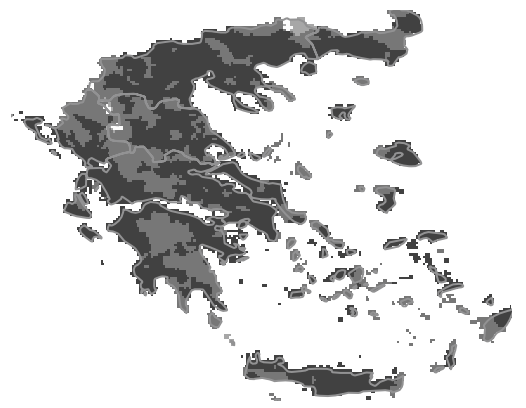

(a) RQ-4A Global Hawk

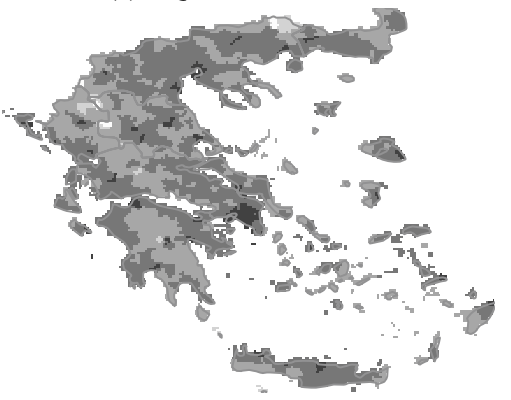

(d) RQ-6 Fire Scout

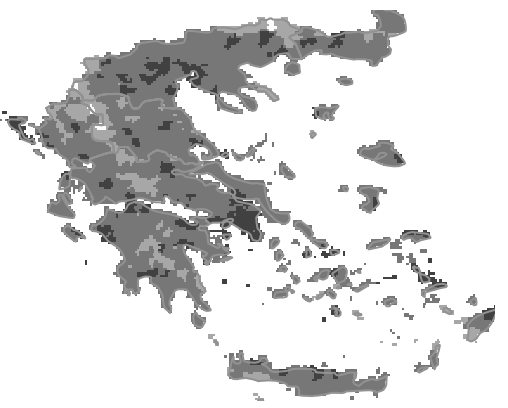

(b) MQ-1 Predator

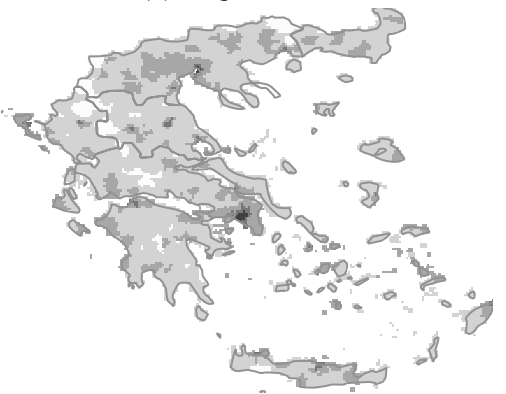

(e) Rmax IIG

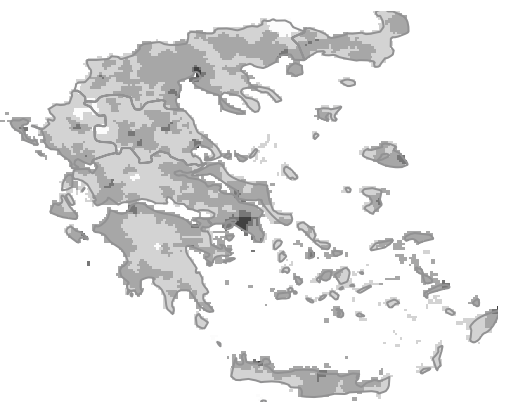

(c) Neptune

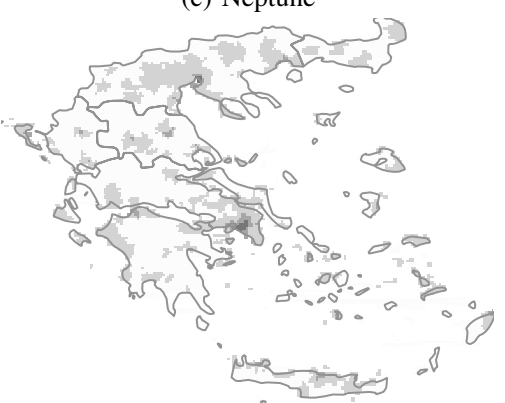

(f) Maxi Joker 2

\begin{tabular}{|ccccc|}
\hline \multicolumn{5}{c|}{ Acceptable $T_{G I}$ in hours to overfly corresponding area } \\
\hline$<10^{2}$ & $10^{2}-10^{3}$ & $10^{3}-10^{4}$ & $10^{4}-10^{5}$ & $>10^{5}$ \\
\hline
\end{tabular}

Fig. 4. The areas of Greece, UAS are allowed to overfly based on their reliability with respect to ground impact occurrence frequency.

through its standard practice document [20], has proposed two certification pathways, one for UAS and one for "Light UAS" where the latter category is based on LSA with the same weight restrictions.

The authors recommend an additional class of 'ultralight UAS', which will include vehicles with weight up to $100 \mathrm{~kg}$ and is also a superset of the mini and micro UAS categories (vehicles up to $10 \mathrm{~kg}$ and $1 \mathrm{~kg}$, respectively) that are also of interest. Fig. 5 illustrates the proposed classification for UAS and corresponding manned aviation classes. This new UAS class is proposed based on the belief that due to the significantly lower risk involved by the operation of ultralight UAS, requirements for their operation will be in the same spirit as the regulation for their manned counterparts. Relaxed requirements at least in class $G$ airspace (unregulated airspace) will allow faster integration of such systems in the NAS. The latter will in turn pave the way for the development of cutting edge UAS technologies, as well as provide a stepping stone for introducing and developing airworthiness regulations and certification procedures for larger unmanned aircraft.

From Table VII it is evident that even with a $T_{G I}$ of 1,000 hours, ultralight UAS have access to more than $90 \%$ of the US area. Furthermore, for the mini category this rises to more than $98 \%$. As a result it can be argued that achieving a $T_{G I}$ of 10,000 hours is sufficient for flying almost anywhere in the US for this class of vehicles. Although in areas of low population density high failure rates can be acceptable in terms of safety, the need for risk mitigation is still evident

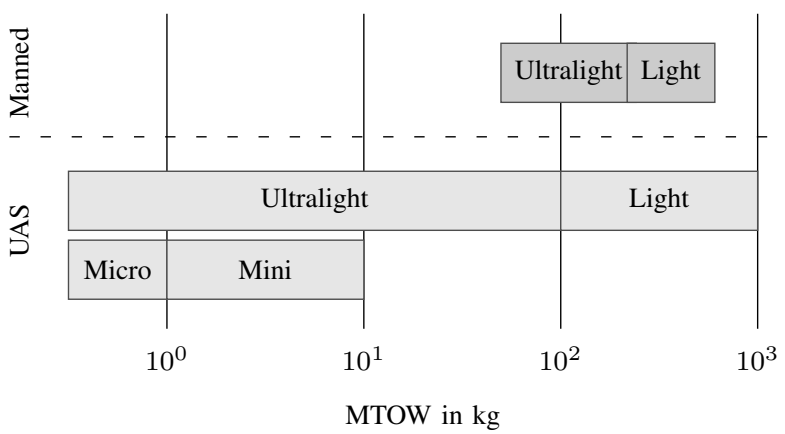

Fig. 5. Proposed UAS classification for vehicles less than $100 \mathrm{~kg}$ and current manned aviation classes in the same MTOW range.

especially for operations in urban, metropolitan regions. This is evident from the reliability required to overfly major metropolitan areas like Houston in Harris County, Texas, presented in Fig. 6.

\section{REFERENCES}

[1] D. R. Haddon and C. J. Whittaker, "Aircraft airworthiness certification standards for civil UAVs," UK Civil Aviation Authority, pp. 79-86, August 2002.

[2] Joint JAA/Eurocontrol Initiative on UAVs, "A concept for european regulations for civil unmanned aerial vehicles (UAV)," Final Report, May 2004.

[3] European Aviation Safety Agency (EASA), "A-NPA, No. 16/2005, policy for unmanned aerial vehicle (UAV) certification," 2005.

[4] R. E. Weibel and R. J. Hansman, "Safety considerations for operation of different classes of uavs in the nas," in AIAA 4th Aviation Tehcnology, Integration and Operations Forum, AIAA 3rd Unmanned Unlimited Technical Conference, Workshop and Exhibit, Sep. 2004. 


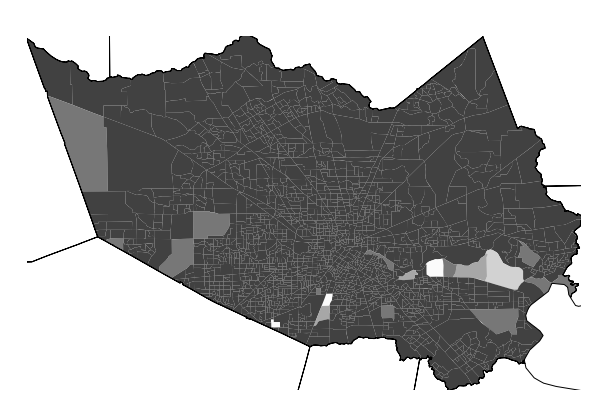

(a) RQ-4A Global Hawk

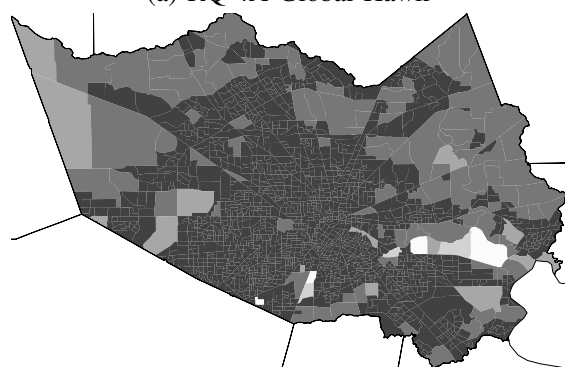

(d) RQ-6 Fire Scout

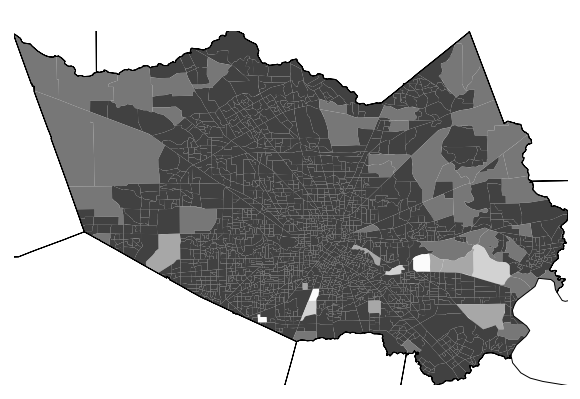

(b) MQ-1 Predator

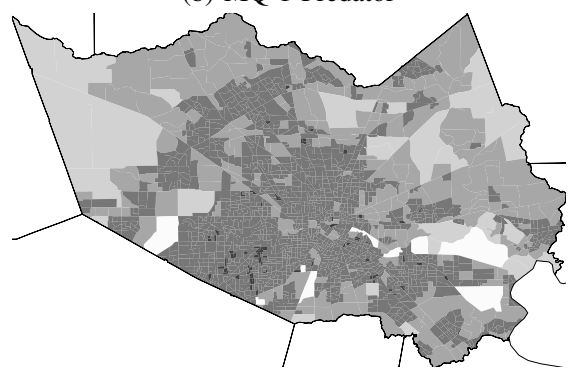

(e) Rmax IIG

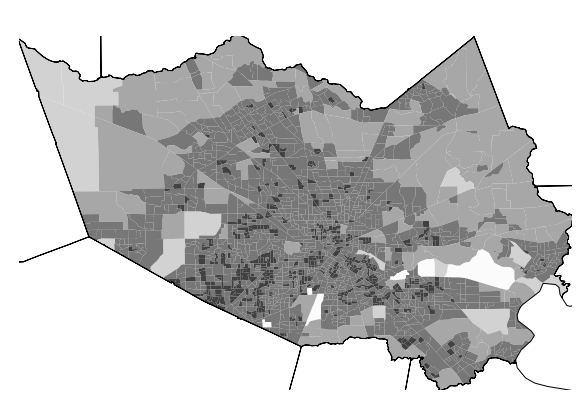

(c) Neptune

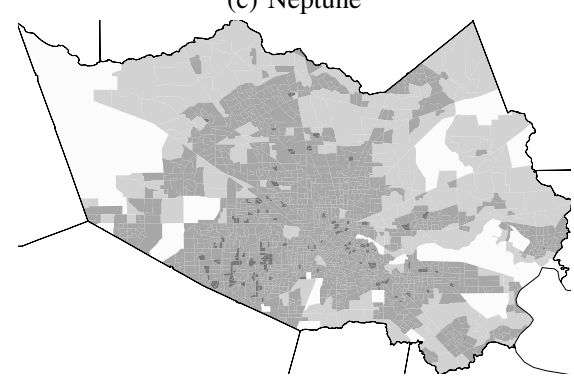

(f) Maxi Joker 2

\begin{tabular}{|ccccc|}
\hline \multicolumn{5}{c|}{ Acceptable $T_{G I}$ in hours to overfly corresponding area } \\
\hline$<10^{2}$ & $10^{2}-10^{3}$ & $10^{3}-10^{4}$ & $10^{4}-10^{5}$ & $>10^{5}$ \\
\hline
\end{tabular}

Fig. 6. The areas of the Harris County, Texas, UAS are allowed to overfly based on their reliability with respect to ground impact occurrence frequency.

TABLE VII

THE PERCENTAGE OF THE US AREA THAT CAN BE OVERFLOWN Without VIOLATING THE TLS OF $f_{F}=10^{-7}$ fatalities $\cdot \mathrm{hr}^{-1}$. THE

RESULTS WERE OBTAINED FOR A SHELTERING FACTOR OF 0.5 .

POPULATION DENSITY DATA SOURCE: [21].

\begin{tabular}{l|c|c|c|c}
\hline & \multicolumn{4}{|c}{$T_{G I}$ in $\mathrm{hr}$} \\
\hline \hline RQ-4A Global Hawk & $10^{2}$ & $10^{3}$ & $10^{4}$ & $10^{5}$ \\
\hline MQ1 Predator & $18.8 \%$ & $29.0 \%$ & $54.3 \%$ & $84.7 \%$ \\
\hline Neptune & $58.1 \%$ & $88.0 \%$ & $73.3 \%$ & $95.4 \%$ \\
\hline RQ-6 Fire Scout & $29.5 \%$ & $55.8 \%$ & $86.1 \%$ & $97.7 \%$ \\
\hline Rmax IIG & $67.2 \%$ & $93.6 \%$ & $98.9 \%$ & $100 \%$ \\
\hline Maxi Joker 2 & $92.0 \%$ & $98.6 \%$ & $100 \%$ & $100 \%$ \\
\hline
\end{tabular}

[5] _ "An integrated approach to evaluating risk mitigation measures for uav operational concepts in the nas," in AIAA 4th Infotech@Aerospace Conderence, Sep. 2005.

[6] T. McGeer, "Aerosonde hazard estimation," The Insitu Group, Tech. Rep., 1994.

[7] T. McGeer, L. R. Newcome, and J. Vagners, "Quantitative risk management as a regulatory approach to civil UAVs," in International Workshop on UAV Certification, June 1999.

[8] R. Clothier and R. Walker, "Determination and evaluation of uav safety objectives," in 21 st International Unmanned Air Vehicle Systems Conference, 2006, pp. 18.1-18.16.

[9] R. Clothier, R. Walker, N. Fulton, and D. Campbell, "A casualty risk analysis for unmanned aerial system (UAS) operations over inhabited areas," in 12th Australian International Aerospace Congress, 2nd Australasian Unmanned Air Vehicles Conference, 2007.

[10] K. J. Hayhurst, J. M. Maddalon, P. S. Miner, M. P. Dewalt, and G. F. Mccormick, "Unmanned aircraft hazards and their implications for regulation," in 25th Digital Avionics Systems Conference, 2006 IEEE/AIAA, 2006, pp. 1-12.
[11] Joint Capability Group on Unmanned Aerial Vehicles, "STANAG 4671 - Unmanned Aerial Vehicle Systems Airworthiness Requirements (USAR)," NATO Naval Armaments Group, draft, Mar 2007.

[12] Range Safety Group, Range Commanders Council, "Range safety criteria for unmanned air vehicles - rationale and methodology supplement," Supplement to document 323-99, Dec 1999.

[13] European Aviation Safety Agency (EASA), "Certification specification 25 (CS25)," Amendment 3, Sep. 2007.

[14] R. E. Weibel and R. J. Hansman, "Safety considerations for operation of small unmanned aerial vehicles in civil airspace," Presented in MIT Joint University Program Quarterly Meeting, Oct 2003.

[15] Range Safety Group, Range Commanders Council, "Common risk criteria standards for national test ranges: Supplement," Supplement to document 321-07, June 2007.

[16] FSF editorial staff, "See what's sharing your airspace," Flight Safety Digest, vol. 24, no. 5, pp. 1-26, May 2005.

[17] Office of the Secretary of Defence, DoD, US, "Unmanned aircraft systems roadmap 2005-2030," Report, 2005.

[18] - "Unmanned aerial vehicle reliability study," Report, 2003

[19] D. R. Haddon and C. J. Whittaker, "UK-CAA policy for light UAV systems," UK Civil Aviation Authority, pp. 79-86, May 2004.

[20] ASTM International, "Standard practice for application of federal aviation administration (FAA) federal regulations part 21 requirements to unmanned aircraft systems (UAS)," Standard F 2505 - 07, Aug 2007.

[21] Center for International Earth Science Information Network (CIESIN), Columbia University and Centro Internacional de Agricultura Tropical (CIAT), "Gridded Population of the World Version 3 (GPWv3): Population Density Grids," Palisades, NY: Socioeconomic Data and Applications Center (SEDAC), Columbia University, 2005. [Online]. Available: http://sedac.ciesin.columbia.edu/gpw 